\title{
Boundary effects across filter spatial scales
}

\author{
Calden Wloka ${ }^{1,2^{*}}$, Neil Bruce ${ }^{3}$, John Tsotsos ${ }^{1,2}$ \\ From The Twenty Third Annual Computational Neuroscience Meeting: CNS*2014 \\ Québec City, Canada. 26-31 July 2014
}

Most saliency algorithms rely on a filter processing stage in which an image is analyzed using a bank of convolution kernels. When applying a convolution to an image, however, a region of pixels with thickness equal to one-half the kernel width at the image border is left undefined due to insufficient input (this undefined region is hereafter referred to as the boundary region). While the percentage of the output image falling within the boundary region is often kept small, this limits the spatial scale of filter which can be applied to the image. There is clear psychophysical evidence from visual search tasks that spatial scale can be used as a component of visual search, with differences in feature size, spatial frequency, and sub-component grouping [1]. Thus, handling filters with dimensions that are significant with respect to the image size is worthwhile if the spatial scale component of visual search is to be effectively incorporated, but this requires dealing with the resulting boundary region.

A large number of computational strategies have been developed over the years for dealing with the boundary region issue, including: image tiling/wrapping, image mirroring, image padding, filter truncation, and output truncation. Formal evaluations and comparisons of such strategies have not previously been performed. We provide such a comparison using visual search stimuli commonly utilized in human psychophysical experiments, as well as propose a novel method for incorporating information across multiple spatial scales with an output image defined up to the boundary region created by the smallest spatial scale.

\section{Acknowledgements}

Financial support was provided in part by the Natural Science and Engineering Research Council (NSERC) and the Canada Research Chairs Program.

\section{Authors' details}

${ }^{1}$ Electrical Engineering and Computer Science, York University, Toronto, ON Canada, M3J 1P3. ${ }^{2}$ Centre for Vision Research, York University, Toronto, ON, Canada, M3J 1P3. ${ }^{3}$ Department of Computer Science, University of Manitoba, Winnipeg, MB, Canada, R3T 2N2.

Published: 21 July 2014

Reference

1. Wolfe Jeremy M: Visual Search. In Attention. Psychology Press; Harold Pashler 1998:

doi:10.1186/1471-2202-15-S1-P19

Cite this article as: Wloka et al:: Boundary effects across filter spatial scales. BMC Neuroscience 2014 15(Suppl 1):P19.

\footnotetext{
* Correspondence: calden@cse.yorku.ca

${ }^{1}$ Electrical Engineering and Computer Science, York University, Toronto, ON, Canada, M3J 1 P3

Full list of author information is available at the end of the article
}

Submit your next manuscript to BioMed Central and take full advantage of:

- Convenient online submission

- Thorough peer review

- No space constraints or color figure charges

- Immediate publication on acceptance

- Inclusion in PubMed, CAS, Scopus and Google Scholar

- Research which is freely available for redistribution

Submit your manuscript at www.biomedcentral.com/submit

\section{() Biomed Central}

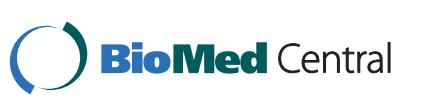

(c) 2014 Wloka et al; licensee BioMed Central Ltd. This is an Open Access article distributed under the terms of the Creative Commons Attribution License (http://creativecommons.org/licenses/by/4.0), which permits unrestricted use, distribution, and reproduction in any medium, provided the original work is properly cited. The Creative Commons Public Domain Dedication waiver (http:// creativecommons.org/publicdomain/zero/1.0/) applies to the data made available in this article, unless otherwise stated. 